\title{
$\begin{array}{ll}\text { Research Square } & \begin{array}{l}\text { Preprints are preliminary reports that have not undergone peer review. } \\ \text { They should not be considered conclusive, used to inform clinical practice, }\end{array} \\ \text { or referenced by the media as validated information. }\end{array}$ \\ Obesity and Telomere Status in the Prognosis of Colorectal Cancer Patients Submitted to Curative Intention Surgical Treatment
}

\section{Sergio García-Martínez}

Universidad Complutense de Madrid

\section{Daniel González-Gamo}

Universidad Complutense de Madrid

\section{Tamara Fernández-Marcelo}

CIBERDEM

\section{Sofía de la Serna}

Hospital Clinico Universitario San Carlos

Inmaculada Serrano

Hospital Clinico Universitario San Carlos

Oscar Cano-Valderrama

Hospital Clinico Universitario San Carlos

\section{Ana Barabash}

Hospital Clinico Universitario San Carlos

\section{Carmen de Juan}

Universidad Complutense de Madrid

\section{Antonio Torres}

Hospital Clinico Universitario San Carlos

Pilar Iniesta ( $\square$ insepi@ucm.es )

https://orcid.org/0000-0002-1259-9810

\section{Research article}

Keywords: Obesity, Telomere status, Colorectal Cancer, Prognosis

Posted Date: May 7th, 2020

DOI: https://doi.org/10.21203/rs.3.rs-25571/v1

License: (c) (i) This work is licensed under a Creative Commons Attribution 4.0 International License. Read Full License

Version of Record: A version of this preprint was published at Molecular and Clinical Oncology on July 3rd, 2021. See the published version at https://doi.org/10.3892/mco.2021.2346. 


\section{Abstract}

Background: Considering that the risk of colorectal cancer (CRC) development has been related to telomere dysfunction and obesity. However, these parameters have not clearly investigated in relation to the clinical evolution of CRC patients. The aim of this study was to evaluate the impact of obesity and telomere status in the prognosis of patients affected by CRC and submitted to curative surgical treatment.

Methods: We performed a prospective study including 162 CRC patients submitted to curative surgical treatment. Subjects were classified according to their Body Mass Index (BMI). Telomere status was established through telomere length and telomerase evaluation. Statistical analyses were performed using the SPSS software package version 22.

Results: Patients with shorter telomeres, both in the tumor (median telomere length $<6.5 \mathrm{~kb}$ ) and their non-tumor paired tissues (median telomere length $<7.1 \mathrm{~kb}$ ), had the best clinical evolution, independently of the Dukes' stage of cancers ( $P=0.025$, for tumor samples; $P=0.003$, for non-tumor samples).

Telomere shortening was inversely associated with BMI in CRC patients. Also, subjects with a BMI $>31.85 \mathrm{~kg} / \mathrm{m}^{2}$ showed the worse clinical outcomes. Of interest, the impact of BMI showed gender dependence, since only the group of men showed significant differences in CRC prognosis in relation to obesity status $(P=0.037)$.

Conclusions: Telomere length constitutes a useful biomarker to predict prognosis in CRC. Independently of BMI values, the better clinical evolution was associated with shorter telomeres. The impact of BMI seems to be related to other factors such as gender.

\section{Background}

Obesity is an emerging and increasingly prevalent condition in the Western world. It is associated with well-known metabolic disorders, leading to the development of different diseases, including cancer (1). Chronic inflammation, a typical feature of obesity, increases the imbalance of the tissue microenvironment, promoting the appearance of the preneoplastic status. In fact, the increase in white adipose tissue (WAT) affects the development of the disease due to the release of several adipokines, interleukins and other cytokines by this type of tissue (2). This causes greater hormonal signaling, increased proliferation and survival of adjacent and distal cells which could induce tumorigenesis (3). Thence, the relationship between body mass index (BMI) and risk of colorectal cancer (CRC) has been the focus of several investigations $(4,5)$, and these studies have shown that an increase in BMI is related to a higher incidence of CRC. However, only few of the publications have shown poorer results for patients with obesity $(6,7)$ and, therefore, the relationship between obesity and the prognosis of CRC has not been widely studied.

As is known, one of the hallmarks in the development of tumorigenesis is the gain of replicative immortality through the maintenance of telomere length (8). Telomeres are a complex of nucleoproteins, which have a fundamental role in the protection of genomic DNA, and they are shortened with each cell cycle of replication due to problems of termination of replication (9). The telomerase enzyme is the main responsible for the maintenance of telomeres (10). The majority of tumors (80-85\%) sustain their capacity to grow indefinitely through the ectopic expression of telomerase, as shown in previous studies $(11,12)$.

Thus, many studies have shown that telomere dysfunction, understood as a critical shortening of telomeres, has a double role in the development of the tumor, since it can act as a tumor suppressor or an oncogenic factor, depending on the cellular context (13). Attrition of telomeres induces the loss of telomere function, which increases genomic instability and activates regulatory molecules such as p53 that lead to senescence and cell death $(14,15)$. On the other hand, this genomic instability causes mutations which could lead to tumorigenesis (16). In addition, it has been 
described that shorter telomeres are found in patients with higher BMI values (17), due to the deteriorated impact of oxidative stress and inflammation on telomeres, suggesting that obesity is related to shortening of telomeres and potentially promoting colorectal carcinogenesis (18-20).

The exposed data highlights the importance of studying how obesity influences telomere function and its potential role as a predictor of prognosis in CRC. The primary aim of the present study was evaluate in CRC the potential prognostic influence of obesity and telomere status, as well as the relationship between both parameters.

\section{Methods}

\section{Patients and Tissue Samples}

One hundred and sixty-two colorectal cancers and their corresponding non-tumor tissue samples, used as controls, were obtained from patients who had undergone potentially curative surgery at San Carlos Hospital in Madrid, Spain, along the last 10 years. Paired samples of non-tumor tissues located at least $10 \mathrm{~cm}$ from the margin of the tumor were obtained and confirmed microscopically.

After surgical resection, all tissue samples were instantly frozen in liquid nitrogen and stored at $-80^{\circ} \mathrm{C}$ until processed. Cryostat-sectioned, Hematoxylin \& Eosin (HE) stained samples from each tumor block were examined microscopically by two independent pathologists to confirm the presence of $\geq 80 \%$ tumor cells.

Cases were collected independently from gender, age of the patient or tumor stage, and no patient had received previous chemo- or radiotherapy before diagnosis and inclusion in the study.

Tumors were pathologically staged according to the modification of the original staging scheme of Dukes by Turnbull et al. (21). Location of the tumor, grade of differentiation and other clinical-pathological features were also recorded. Patients were classified according to their BMI values following the criteria of the World Health Organization (WHO). Thus, patients with $\mathrm{BMI}<25 \mathrm{~kg} / \mathrm{m}^{2}$ were considered to have normal weight; patients with $\mathrm{BMI} \geq 25 \mathrm{~kg} / \mathrm{m}^{2}$ and $\leq$ $29.9 \mathrm{~kg} / \mathrm{m}^{2}$, as overweight; and people with obesity were defined as a BMI $\geq 30 \mathrm{~kg} / \mathrm{m}^{2}$.

The mean follow-up period of the series was 5 years (range, 1-147 months). Follow-up was defined by the elapsed time between surgery and last clinical evaluation of the patient during the study period or death of the patient. Recurrence was defined as the appearance, during follow-up, of any local or distant lesion related to the tumoral process. Disease free survival (DFS) was assessed from the day of surgery until confirmed recurrence.

Informed consent was obtained from patients prior to investigation. This study was approved by the Ethical Committee of the Hospital, assuring the patients the confidentiality of their data.

\section{Telomere length and Telomerase activity evaluation}

The mean telomere length (MTL) values were obtained by the Terminal Restriction Fragment (TRF) length procedure. TRF measurement was performed using Telo TTAGGG Telomere Length Assay kit, Cat No. 12209136001 (Roche Applied Science, Penzberg, Germany) as previously described (9).

The TRF lengths for tumors and control non-tumoral tissues were determined by comparing the signals with respect to a standard molecular weight, using Image Gauge software version 3.46 (Fujifilm, Tokyo, Japan).

The length ratio of TRF was determined as the delta of the TRF length of tumors and the TRF of their non-tumor paired samples ( $\mathrm{T} / \mathrm{N}$ ratio). 
The shortening or lengthening of the TRF was defined if the TRF length of the tumor tissues was respectively, shorter or longer than their corresponding non-tumor tissues.

In colorectal samples, telomerase was measured using the Telomeric Repeat Amplification Protocol (TRAP)-based telomerase polymerase chain reaction (PCR)-enzyme-linked immunosorbent assay (ELISA) kit Cat No. 11854666910 (Roche Applied Science, Penzberg, Germany), which allowed us to establish a semiquantitative assay (22). Thus, considering that the cut-off for TRAP-ELISA negativity corresponds to an optical density $\mathrm{OD}_{450 \mathrm{~nm}}<0.2$, all samples with $\mathrm{OD}_{450 \mathrm{~nm}} \geq 0.2$ were considered telomerase positive (23).

\section{Statistical Analysis}

Statistical analyses were performed using the SPSS software package version 22 (SPSS Inc., Chicago, IL, USA). Differences in two or more groups of study were calculated by parametric (ANOVA and Student-T) or non-parametric tests (Kruskal-Wallis and Mann-Whitney $\mathrm{U}$ ), depending on normality (based on Kolmogorov-Smirnov test) and homoscedasticity conditions of the variables used in this study. To compare the means of two related variables, Wilcoxon test was executed. Chi-square test was employed to compare categorical, and correlations were assessed by Spearman test. P-values $<0.05$ were considered statistically significant.

Disease-free survival (DFS) was calculated was calculated using the Kaplan-Meier method and differences were evaluated by the Log-rank test. Patients with Dukes D-stage tumors or those who died in the postoperative period were excluded from the survival analysis. The mark of censored data indicated the end of an individual follow-up period. The potential prognostic impact of the variables considered in this work jointly, were evaluated by Cox multivariate regression analyses. Cutoff Finder Web Application (http://molpath.charite.de/cutoff/) (24) was used to determine the cut-off points for prognosis analysis.

\section{Results}

In total, $162 \mathrm{CRC}$ patients were included in the study, 82 females and 80 males with a mean age of $70.6 \pm 0.9$ years. Mean age was comparable among both genders (female: $70.3 \pm 1.4$ years vs male: $71.0 \pm 1.2 ; P=0.905$ ). BMI data was available for 125 cases, 63 female and 62 males. Overall, 34 patients showed "normal weight"; 57 were classified as "overweight"; and 34 were cataloged as "people with obesity", without significant differences in relation to gender $(\mathrm{P}=$ 0.286). Moreover, BMI groups did not show significant associations with respect to Dukes stage $(P=0.239)$ nor tumor location $(P=0.347)$ (Table 1$)$. 


\begin{tabular}{|c|c|c|c|c|c|}
\hline \multicolumn{6}{|c|}{ BMI (BODY MASS INDEX) $\left(\mathrm{kg} / \mathrm{m}^{2}\right)$} \\
\hline VARIABLES & $N^{0}$ of cases & $\begin{array}{l}\text { NORMOWEIGHT } \\
(\mathrm{BMI}<25)\end{array}$ & $\begin{array}{l}\text { OVERWEIGHT } \\
(\mathrm{BMI}=\mathbf{2 5 - 2 9 . 9 )}\end{array}$ & $\begin{array}{l}\text { OBESITY } \\
(\mathrm{BMI} \geq 30)\end{array}$ & P; Chi-square test \\
\hline GENDER & 125 & 34 & 57 & 34 & \\
\hline FEMALE & 63 & 15 & 27 & 21 & $P=0.286$ \\
\hline MALE & 62 & 19 & 30 & 13 & \\
\hline DUKES STAGE & 125 & 34 & 57 & 34 & \\
\hline$A$ & 19 & 7 & 6 & 6 & $P=0.232$ \\
\hline B & 60 & 13 & 34 & 13 & \\
\hline C & 33 & 11 & 10 & 12 & \\
\hline D & 13 & 3 & 7 & 3 & \\
\hline TUMOR LOCATION & 125 & 34 & 57 & 34 & \\
\hline RIGHT COLON & 46 & 11 & 22 & 13 & $P=0.250$ \\
\hline LEFT COLON & 33 & 9 & 19 & 5 & \\
\hline RECTUM & 46 & 14 & 16 & 16 & \\
\hline
\end{tabular}

Table 1

Body Mass Index (BMI) and clinic-pathological variables in Colorectal Cancer patients

Telomere function was established through telomere length determination and telomerase activity evaluation, both in tumor and non-tumor samples from 138 and 162 patients, respectively. MTL in tumor tissues was $6.11 \pm 0.20 \mathrm{~kb}$, whereas in non-tumor tissues MTL was $8.22 \pm 0.27 \mathrm{~kb}$. A positive correlation was detected between telomere length in tumor and its paired non-tumor samples $(r=0.501, P<0.001)$. Moreover, an inverse correlation was found between non-tumor and tumor telomere length and the age of patients $(r=-0.170, P=0.028$ for non-tumor tissues, and $r=-$ $0.155 ; \mathrm{P}=0.041$ for tumor samples).

The mean value for telomere length in tumor and non-tumor samples was correlated with Dukes' stage, as the lowest mean value was observed in earlier Dukes' stage cancers ( $P=0.016$ for tumor samples) (Table 2). Overall, telomere shortening was detected in $\mathrm{CRC}$, as demonstrated by the $\mathrm{T} / \mathrm{N}$ ratio values $(0.78 \pm 0.02)$. $\mathrm{T} / \mathrm{N}$ ratio values were significantly associated with $\mathrm{BMl}$; in fact, patients with obesity and CRC showed less shortening of tumor telomeres $(0.85 \pm 0.05)$ than the rest of the non-obese patients affected with CRC $(0.72 \pm 0.03)(P=0.047)$.

Telomerase activity was positive in 121 (75.9\%) of the 162 cases, while 41 (24.1\%) of the CRC were telomerase negative. As shown in Table 2, a significantly higher proportion of tumors of the right colon (45.1\%) resulted negative for telomerase, compared to other locations of the tumors ( $18.9 \%$ of tumors from the left colon, or $14.7 \%$ of tumors from the rectum), with significant differences $(P<0.001)$. 
Table 2

Telomere status and clinic-pathological variables in Colorectal Cancer patients

\begin{tabular}{|c|c|c|c|c|c|c|c|c|c|}
\hline \multirow[b]{2}{*}{ VARIABLE } & \multicolumn{5}{|c|}{$\begin{array}{l}\text { Telomere length (Kilobase pairs; mean } \pm \text { standard } \\
\text { error) }\end{array}$} & \multicolumn{4}{|c|}{ Telomerase activity } \\
\hline & $\begin{array}{l}N^{0} \text { of } \\
\text { cases }\end{array}$ & $\begin{array}{l}\text { Tumor } \\
\text { Samples }\end{array}$ & $\begin{array}{l}\text { P and } \\
\text { test } \\
\text { statistic }\end{array}$ & $\begin{array}{l}\text { Non- } \\
\text { tumor } \\
\text { samples }\end{array}$ & $\begin{array}{l}\text { P and } \\
\text { test } \\
\text { statistic }\end{array}$ & $\begin{array}{l}N^{0} \text { of } \\
\text { cases }\end{array}$ & Positive & Negative & $\begin{array}{l}\mathrm{P} ; \text { Chi } \\
\text { square } \\
\text { test }\end{array}$ \\
\hline GENDER & 138 & & & & & 162 & 121 & 41 & \\
\hline FEMALE & 73 & $\begin{array}{l}621 \pm \\
0.29\end{array}$ & $\begin{array}{l}P= \\
0.423\end{array}$ & $\begin{array}{l}8.14 \pm \\
0.36\end{array}$ & $\begin{array}{l}P= \\
0.908\end{array}$ & 82 & 63 & 19 & $\begin{array}{l}P= \\
0.526\end{array}$ \\
\hline MALE & 65 & $\begin{array}{l}6.21 \pm \\
0.29\end{array}$ & $\begin{array}{l}\text { IVlann- } \\
\text { Whitney } \\
\text { U test }\end{array}$ & $\begin{array}{l}8.43 \pm \\
0.48\end{array}$ & $\begin{array}{l}\text { Mlann- } \\
\text { Whitney } \\
\text { U test }\end{array}$ & 80 & 58 & 22 & \\
\hline $\begin{array}{l}\text { DUKES } \\
\text { STAGE } \\
\text { A\&B vS. } \\
\text { C\&D }\end{array}$ & 138 & & & & & 162 & 121 & 41 & \\
\hline$A \& B$ & 81 & $\begin{array}{l}5.65 \pm \\
0.25\end{array}$ & $\begin{array}{l}P= \\
0.016\end{array}$ & $\begin{array}{l}7.85 \pm \\
0.33\end{array}$ & $\begin{array}{l}P= \\
0.132\end{array}$ & 88 & 68 & 20 & $\begin{array}{l}P= \\
0.410\end{array}$ \\
\hline C\&D & 57 & $\begin{array}{l}6.66 \pm \\
0.34\end{array}$ & $\begin{array}{l}\text { Whitney } \\
\text { U test }\end{array}$ & $\begin{array}{l}8.87 \pm \\
0.54\end{array}$ & $\begin{array}{l}\text { Whitney } \\
\text { U test }\end{array}$ & 74 & 53 & 21 & \\
\hline $\begin{array}{l}\text { TUMOR } \\
\text { LOCATION }\end{array}$ & 138 & & & & & 162 & 121 & 41 & \\
\hline $\begin{array}{l}\text { RIGHT } \\
\text { COLON }\end{array}$ & 43 & $\begin{array}{l}5.40 \pm \\
0.32\end{array}$ & $\begin{array}{l}P= \\
0.075\end{array}$ & $\begin{array}{l}8.36 \pm \\
0.70\end{array}$ & $\begin{array}{l}P= \\
0.060\end{array}$ & 51 & 28 & 23 & $\begin{array}{l}P< \\
0.001\end{array}$ \\
\hline $\begin{array}{l}\text { LEFT } \\
\text { COLON }\end{array}$ & 33 & $\begin{array}{l}6.60 \pm \\
0.53\end{array}$ & $\begin{array}{l}\text { Kruskall- } \\
\text { Wallis }\end{array}$ & $\begin{array}{l}9.34 \pm \\
0.58\end{array}$ & $\begin{array}{l}\text { Kruskall- } \\
\text { Wallis }\end{array}$ & 37 & 30 & 7 & \\
\hline RECTUM & 62 & $\begin{array}{l}6.24 \pm \\
0.28\end{array}$ & test & $\begin{array}{l}7.65 \pm \\
0.30\end{array}$ & test & 74 & 63 & 11 & \\
\hline
\end{tabular}

Regarding telomere status, the outcomes of the patients were analyzed considering the optimal cut-off values for the mean length of the tumor telomeres, as established in a previous publication of our research team (12). With respect to the CRC population included in the present manuscript, patients whose tumors showed an MTL $<6.5 \mathrm{~kb}$ showed the best clinical evolution (Fig. 1A), regardless of Dukes' stage of the tumor, as corroborated by Cox's multivariate analysis (Table 3A). Therefore, colorectal tumors with an $\mathrm{MTL}<6.5 \mathrm{~kb}$ conferred a decreased relative risk of recurrence more than five times lower than that of tumors showing an $M T L \geq 6.5 \mathrm{~kb}(\mathrm{RR}=0.169,95 \% \mathrm{Cl}=0.036-0.700 ; \mathrm{P}=0.025)$.

\begin{tabular}{|llll|}
\hline \multicolumn{3}{|l|}{ Multivariate Analysis } \\
\hline Variable & P & RR $^{\#}$ & Cl\#\# $^{\# \mid}$ \\
\hline Dukes stage A \& B vs. C & 0.004 & 4.69 & 1.66 to 13.24 \\
\hline Tumor MTL* in CRC, < 6.5 Kb vs. $\geq 6.5$ Kb & 0.025 & 0.169 & 0.036 to 0.80 \\
\hline *Mean Telomere Length; **Body Mass Index; ${ }^{*}$ Relative Risk; ${ }^{\# \#}$ Confidence Interval \\
\hline
\end{tabular}


Table 3

Multivariate Cox Regression Analysis in Colorectal Cancer patients

Moreover, when survival was analyzed considering the MTL data in non-tumoral tissues, a better clinical evolution was found in the group of patients who showed MTL values $<7.1 \mathrm{~kb}(P=0.003)$ (Fig. 1B). It was not mathematically possible to establish the Cox multivariate study considering MTL data in non-tumor tissues, because one subset of events was empty (no cases of recurrence within the group of $M T L<7.1 \mathrm{~kb}$ ), and we would have obtained an undefined value for RR.

Concerning BMI, the optimal cut-off values for the BMI were calculated using the Cutoff Finder Web Application (24). Patients with a $\mathrm{BMI}>31.85$ showed a significantly worse prognosis compared to the group of patients with a BMI< 31.85 ( $P=0.034)$ (Fig. 2). These results were not independent of the gender of the patients included in this study.

As shown in Fig. 3, males with a BMI higher than 31.85 showed a significantly worse prognosis compared to males with a BMI lower than $31.85(P=0.037)$ (Fig. $3 A)$. For females, however, such differences were not evident $(P=0.388)$ (Fig. 3B).

When the two variables (telomere status and $\mathrm{BMI}$ ) were considered together in relation to the prognosis of the patients affected by the $\mathrm{CRC}$, our results indicated that the telomere status constitutes a definitive molecular parameter to establish the prognosis of patients.

In fact, independently of the BMI, patients affected with cancers showing the lowest values of average telomere length, both in tumor and non-tumor samples, showed the best clinical evolution (Fig. 4A and 4B, for tumor tissues, $P<0.001$; and Figs. 5A and $5 \mathrm{~B}$, for non-tumor tissues, $\mathrm{P}<0.001)$.

\section{Discussion}

There is growing evidence that inflammation is a central and reversible mechanism through which obesity promotes cancer risk and progression. The tumoral promoting effects of obesity occur locally through the inflammation of adipose tissue and the associated alterations in the microenvironment (2). Therefore, the characterization of biomarkers to identify patients with obesity with high-risk CRC seems of paramount in order to contribute to an early diagnosis and improvement in the election of the most appropriate therapeutic protocols.

In this context, considering that telomere shortening has been associated with obesity in several studies, and that telomere maintenance is critical for the progression of cancer, our study was carried out considering a large population of CRC patients, with and without obesity, submitted to surgery with curative intention. Results from this work allowed us to demonstrate that telomere status is related to obesity and clinical prognosis.

Although the activity of telomerase was positive in most of the tumors considered in our study, we detected a significant shortening of telomeres in the tumor samples compared to the mean values of the telomere length observed in the non-tumoral paired tissues, as previously reported by others $(12,25)$. Furthermore, according to the results obtained in the present investigation, the lower mean values of telomere length, both in tumors and in their nontumoral paired tissues, were associated with earlier stages of Dukes, in agreement with other groups (26). Thus, these data prove that shorter telomeres are associated with cancers that, a priori, would confer a better prognosis to patients with CRC. In addition, our results indicate that cancers displaying lower values of shortening of telomere length, occur in patients with obesity. We consider these data of interest since, although several studies have established a link between obesity and the risk of colon cancer, little is known about the effect of obesity on the outcomes after diagnosis (7). 
It has been reported that a BMI greater than $35.0 \mathrm{~kg} / \mathrm{m}^{2}$ at the time of diagnosis in patients with colon cancer is associated with an increased risk of recurrence (7). However, other authors have not confirmed these data, nor a significant correlation between BMI and an increased risk of death in patients with CRC (27). It has also been suggested that BMI prior to diagnosis is an important predictor of survival among patients with non-metastatic CRC (6). More recently, Bhaskaran et al. have reported that heterogeneity in the effects of BMI suggests different mechanisms or combinations of mechanisms associated with different tumor locations and in different subgroups of patients (5).

In our study, the group of patients with BMI values greater than $31.85 \mathrm{~kg} / \mathrm{m}^{2}$, showed a significantly worse clinical prognosis. However, Cox multivariate regression analyses did not demonstrate that these results were independent of the Dukes tumor stage.

Interestingly, our results indicate significant differences according to the gender: when the effect of obesity on the prognosis of patients with CRC was analyzed, these differences were only evident in the male population. Although this fact could be explained by considering the relationship between gender and fat distribution (28), other aspects might be further investigated, including additional genetic, hormonal or molecular mechanisms, in order to explain the effect of obesity on the prognosis of CRC related to the gender of patients (29).

With respect to the telomere status, our data support that the prognosis of patients with CRC, whether with or without obesity, is strongly related to the length of the tumor telomere, being these results independent of the stage of the tumor.

In the present study we have identified a specific length of telomere in non-tumoral tissues that seems critical to predict the prognosis of cancer. Therefore, patients with a telomere length less than $7.1 \mathrm{~kb}$ in non-tumoral tissues present a better clinical evolution, considering both subjects with and without obesity. At this point, our results would support the idea that carcinogenic cells have a common biological history with normal tissue (30).

These data allow us to hypothesize the possibility that tumor cells with shorter telomeres activate cellular senescence, thereby conferring a more favorable clinical prognosis to patients affected by CRC. In fact, the progressive shortening of telomeres results in the formation of dysfunctional telomeres that compromise tissue proliferation (15).

The shortening of human telomeres has two opposite effects during the development of cancer. On the one hand, the shortening of telomeres can exert a tumor suppressive effect through the arrest of proliferation. On the other hand, the loss of telomere protection can lead to a telomere crisis, which is a state of extensive genomic instability that can promote the progression of cancer (13). Our research team has previously reported data in CRC that support a worse clinical evolution in patients with maintenance of tumor telomeres (12).

In conclusion, in the present study we have jointly evaluated the prognostic relevance of obesity and telomere status in patients affected by CRC who had undergone surgery of curative intention. Our results demonstrate that the length of telomeres is a useful biomarker to predict the clinical outcome in these subjects. Patients with shorter telomeres, both in the tumoral and their non-tumoral paired tissues, had the best clinical evolution, independently of the Dukes' stage. Our data allow us to conclude that patients with obesity had a poorer prognosis, however, these results were not independent from the tumoral Dukes' stage.

Further investigations are needed to analyze the effect of obesity on the clinical course of CRC in the context of other factors, such as the gender of the patients. 


\section{Abreviations}

BMI: Body Mass Index; CRC: Colorectal Cancer; DFS: Disease Free Survival; HE: Hematoxiline \& Eosin; MTL: Mean

Telomere Length; NT-MTL: Non-Tumoral Mean Telomere Length; T-MTL: Tumoral Mean Telomere Length; TRAP:

Telomeric Repeat Amplification Protocol; TRF: Terminal Restriction Fragment; WAT: White Adipose Tissue; WHO: World Health Organization.

\section{Declarations}

\section{Ethics approval and consent to participate.}

This study was approved by the Ethical Committee of the San Carlos Hospital (Madrid, Spain). Informed consents were obtained from patients prior to investigation assuring the confidentiality of their data.

\section{Consent for publication.}

Not applicable.

\section{Availability of data and materials.}

The datasets generated and analyzed in this work are available from the corresponding author.

\section{Competing interests.}

Authors declare that there no exists any conflict of interests.

\section{Funding.}

This work was supported by grant PI15/01199 from the Carlos III Institute of Health (Ministerio de Economía y Competitividad), Spain. Funders did not participate in study design, data collection and analysis, decision to publish, nor preparation of the manuscript.

\section{Author's contributions.}

Conceived and designed the study: AT, PI. Performed the assays: SGM, DGG, TFM. Monitoring of patients and Collection of clinical data: SdIS, IS, OCV, AB, AT. Analyzed the data: SGM, DGG, TFM, AB, CdJ, AT, PI. Wrote the paper: SGM, DGG, SdIS, PI.

\section{Aknowledgments.}

Not applicable.

\section{References}


1. Kolb R,Sutterwala FS, Zhang W. Obesity and cancer: inflammation bridges the two. Curr Opin Pharmacol. 2016;29:77-89.

2. lyengar NM,Gucalp A, Dannenberg AJ, Hudis CA. Obesity and cancer mechanism: tumor microenviroment and inflammation. J Clin Oncol. 2016;34:4270-6.

3. lyengar NM,Hudis CA, Dannenberg AJ. Obesity and cancer: local and systematic mechanisms. Annu Rev Med. 2015;66:297-309.

4. Guh DP,Zhang W, Bansback N, Amarsi Z, Birmingham CL, Anis AH. The incidence of co-morbidities related to obesity and overweight: a systematic review and meta-analysis. BMC Public Health. 2009;9:1-20.

5. Bhaskaran K,Douglas I, Forbes H, dos-Santos-Silva I, Leon DA, Smeeth L. BMI and risk of 22 specific cancers: a population-based cohort study of 5.24 million UK adults. 2014;384:755-65.

6. Campbell PT, Newton CC, Dehal AN, Jacobs EJ, Patel AV, Gapstur SM. Impact of body mass index on survival after colorectal cancer diagnosis: the cancer preventions Study-II nutrition cohort. J Clin Oncol. 2012;30:42-52.

7. Dignam JJ, Polite BN, Yothers $\mathrm{G}$ et al. Body mass index and outcomes in patients who receive adjuvant chemotherapy for colon cancer. J Natl Cancer Inst. 2006;98:1647-54.

8. Hanahan D,Weinberg RA. Hallmarks of cancer: the next generation. 2011;144:646-74.

9. Wu RA,Upton HE, Vogan JM, Collins K. Telomerase mechanism of telomere synthesis. Annu Rev Biochem. 2017;86:439-60.

10. Schmidt JC,Cech TR. Human telomerase: biogenesis, trafficking, recruitment, and activation. Genes Dev. 2015;29:1095-105.

11. Garcia-Aranda C,de Juan C, Diaz-Lopez A et al. Correlations of telomere length, telomerase activity, and telomericrepeat binding factor 1 expression in colorectal carcinoma. Cancer. 2006;106:541-51.

12. Fernández-Marcelo T,Sánchez-Pernaute A, Pascua I et al. Clinical relevance of telomere status and telomerase activity in colorectal cancer. PLoS One. 2016;11:1-12.

13. Maciejowski J,de Lange T. Telomeres in cancer: tumor suppression and genome instability. Nat Rev Mol Cell Biol. 2017;18:175-86.

14. Feldser DM, Greider CW. Short telomeres limit tumor progression in vivo by inducing senescence. Cancer Cell. 2007;11:461-9.

15. Wang Y,Wang X, Flores ER, Yu J, Chang S. Dysfunctional telomeres induce p53-dependent and independent apoptosis to compromise cellular proliferation and inhibit tumor formation. Aging Cell. 2016;15:646-60.

16. Roger L, Jones RE, Heppel NH, Williams GT, Sampson JR, Baird DM. Extensive telomere erosion in the initiation of colorectal adenomas and its association with chromosomal instability. J Natl Cancer Inst. 2013;105:1202-11.

17. Mundstock E, Sarria EE, Zatti H et al. Effect of obesity on telomere length: systematic review and meta-analysis. Obesity (Silver Spring). 2015;23:2165-74.

18. An R,Yan H. Body weight status and telomere length in U.S. middle-aged and older adults. Obes Res Clin Pract. 2017; 11:51-62.

19. Correia-Melo C, Hewitt G, Passos JF. Telomeres, oxidative stress and inflammatory factors: partners in cellular senescence? Longev Healthspan. 2014;3:1-9.

20. Masi S, Salpea KD, Li K et al. Oxidative stress, chronic inflammation, and telomere length in patients with periodontitis. Free Radic Biol Med. 2011;50:730-5.

21. Turnbull RB Jr, Kyle K, Watson FR, Spratt J: Cancer of the colon: the influence of the no-touch isolation technic on survival rates. Ann Surg. 1967;166:420-7. 
22. González-Quevedo R, Iniesta P, Morán A et al. Cooperative role of telomerase activity and p16 expression in the prognosis of nonsmall-cell lung cancer. J Clin Oncol. 2002;20:254-62.

23. Frías C, García-Aranda C, de Juan C et al. Telomere shortening is associated with poor prognosis and telomerase activity correlates with DNA repair impairment in non-small cell lung cancer. Lung Cancer 2008;60:416-25.

24. Budczies J, Klauschen F, Sinn BV et al. Cutoff Finder: a comprehensive and straightforward web application enabling rapid biomarker cutoff optimization. PLoS One. 2012;7:1-7.

25. Bertorelle R, Rampazzo E, Pucciarelli S, Nitti D, De Rossi A. Telomeres, telomerase and colorectal cancer. World J Gastroenterol. 2014;20:1940-50.

26. Jia $\mathrm{H}$, Wang Z. Telomere length as a prognostic factor for overall survival in colorectal cancer patients. Cell Physiol Biochem. 2016;38:122-8.

27. Meyerhardt JA, Niedzwiecki D, Hollis D et al. Impact of body mass index and weight change after treatment on cancer recurrence and survival in patients with stage III colon cancer: findings from cancer and leukemia group $B$ 89803. J Clin Oncol. 2008;26:4109-15.

28. Doleman B, Mills KT, Lim S, Zelhart MD, Gagliardi G. Body mass index and colorectal cancer prognosis: a systematic review and meta-analysis. Tech Coloproctol. 2016;20:517-35.

29. Cheung WY, Shi Q, O'Connell M et al. The predictive and prognostic value of sex in early-stage colon cancer: a pooled analysis of 33,345 patients from the ACCENT database. Clin Colorectal Cancer. 2013;12:179-87.

30. Nakamura K, Furugori E, Esaki Y I et al. Correlation of telomere lengths in normal and cancers tissue in the large bowel. Cancer Lett. 2000;158:179-84.

\section{Figures}


Figure 1

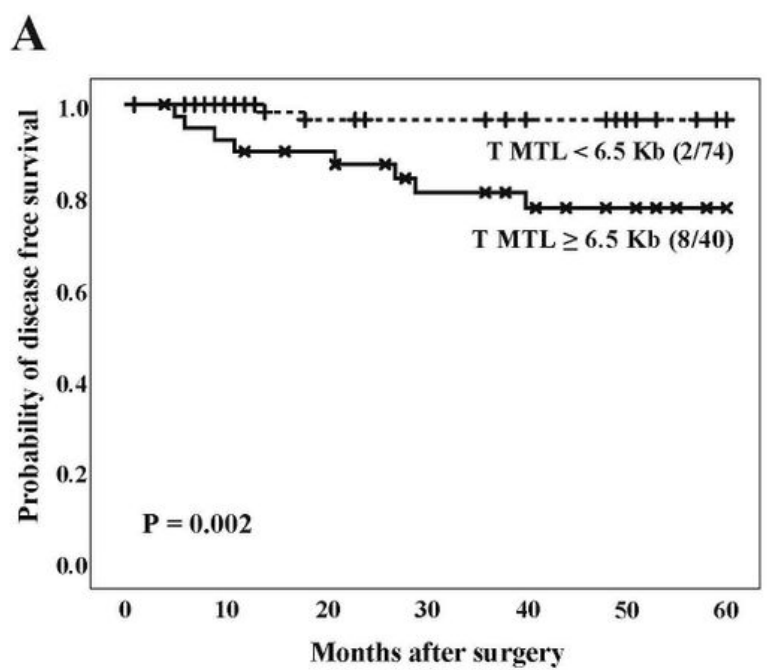

B

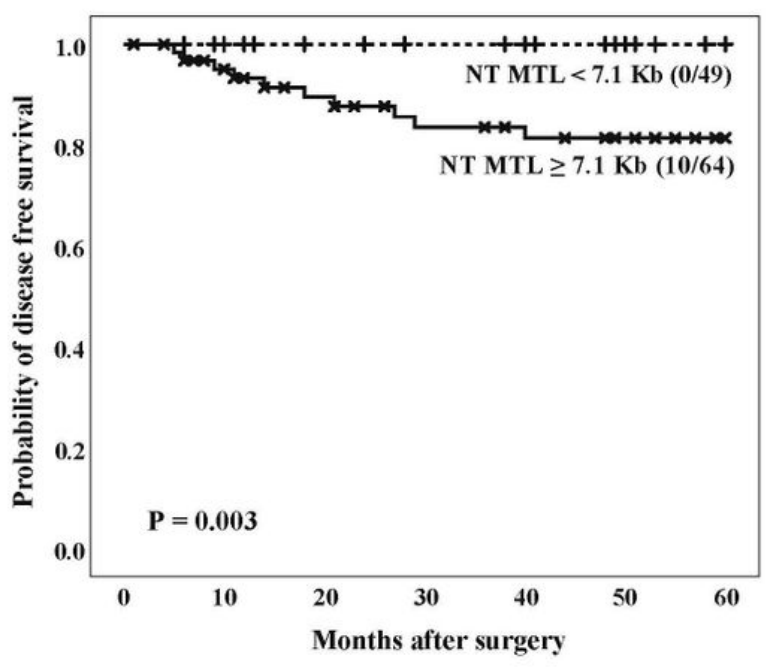

Figure 1

Kaplan-Meier plots of Disease Free Survival (DFS) considering telomere length. Kaplan-Meier survival curves in relation to mean telomere length in tumor samples (T-MTL) (A), and non-tumoral samples (NT-MTL) (B), in Colorectal Cancer population. Numbers in brackets represent cases with tumor recurrence and crosses indicate censored data. 


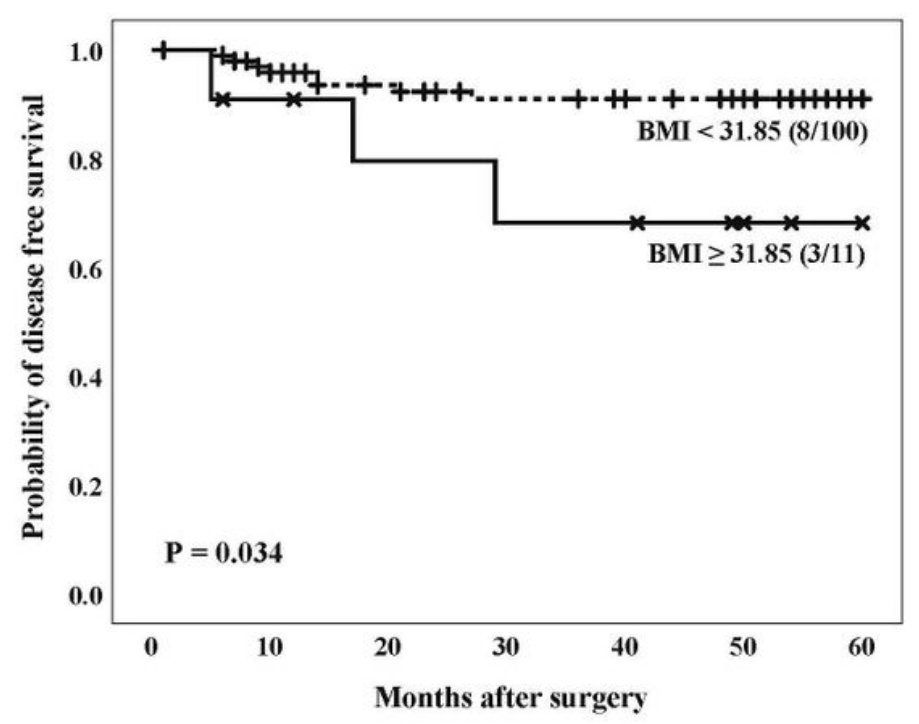

\section{Figure 2}

Kaplan-Meier plots of Disease Free Survival (DFS) considering BMI. Kaplan-Meier survival curves in relation to a Body Mass Index (BMI) of $31.85 \mathrm{~kg} / \mathrm{m} 2$ in patients affected by Colorectal Cancer. Numbers in brackets represent cases with tumor recurrence and crosses indicate censored data. 


\section{Figure 3}

A

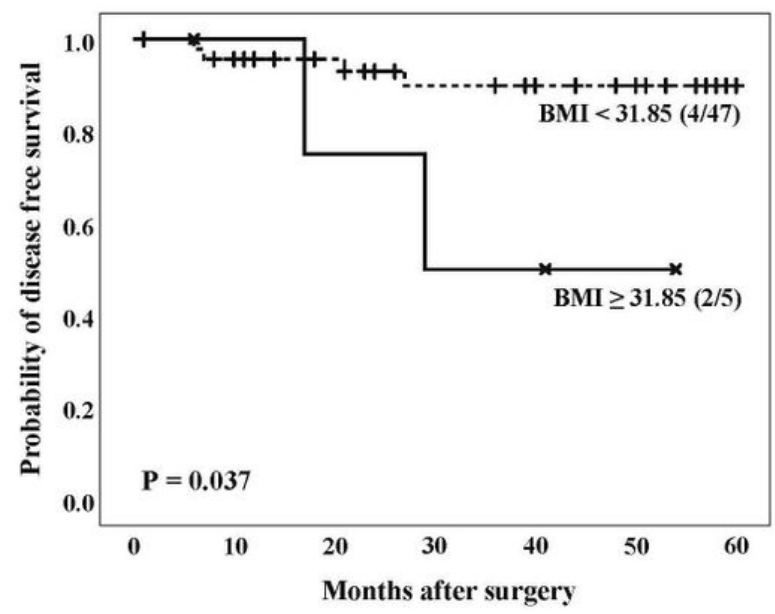

B

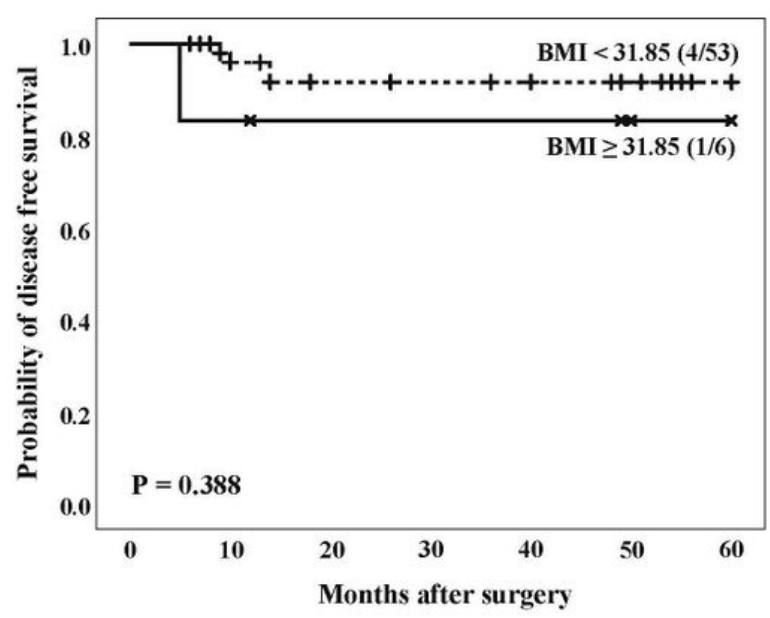

\section{Figure 3}

Kaplan-Meier plots of Disease Free Survival (DFS) considering BMI and gender of subjects. Kaplan-Meier survival curves in relation to a Body Mass Index (BMI) $<31.85 \mathrm{~kg} / \mathrm{m} 2$ or $\geq 31.85 \mathrm{~kg} / \mathrm{m} 2$ in male (A) and female (B) in Colorectal Cancer population. Numbers in brackets represent cases with tumor recurrence and crosses indicate censored data. 
Figure 4

A

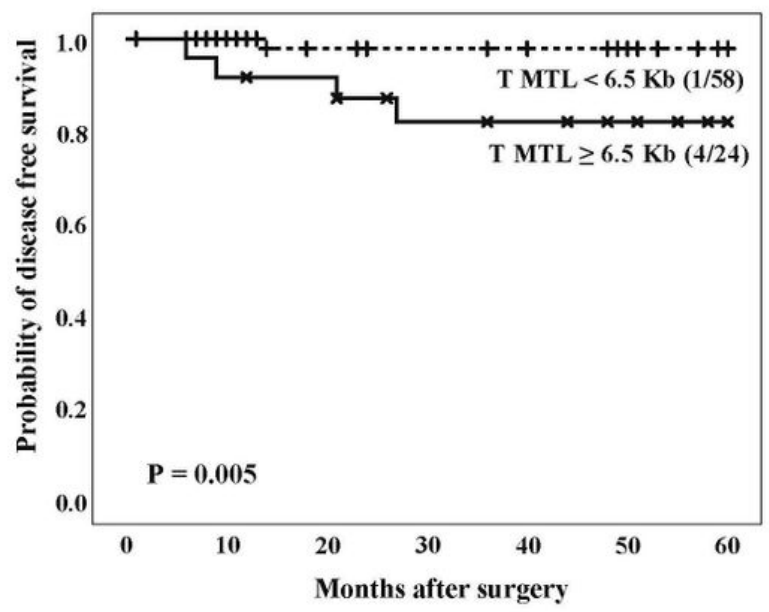

B

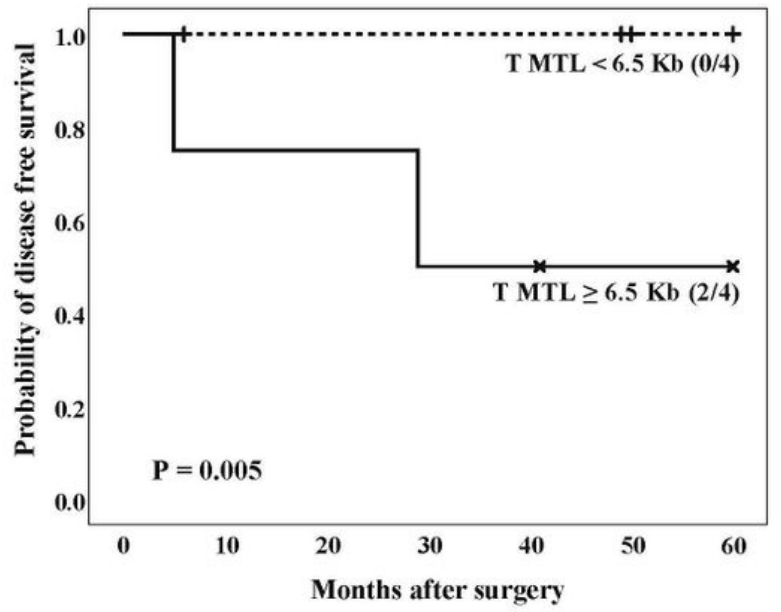

\section{Figure 4}

Kaplan-Meier plots of Disease Free Survival (DFS) considering T-MLT and BMI of patients. Kaplan-Meier curves in relation to Tumor Mean Telomere Length (T-MTL) and Body Mass Index (BMI) in Colorectal Cancer population: (A) BMI $<31.85 \mathrm{~kg} / \mathrm{m} 2$ and $(\mathrm{B}) \mathrm{BMI} \geq 31.85 \mathrm{~kg} / \mathrm{m} 2$. Numbers in brackets represent cases with tumor recurrence and crosses indicate censored data. 
Figure 5
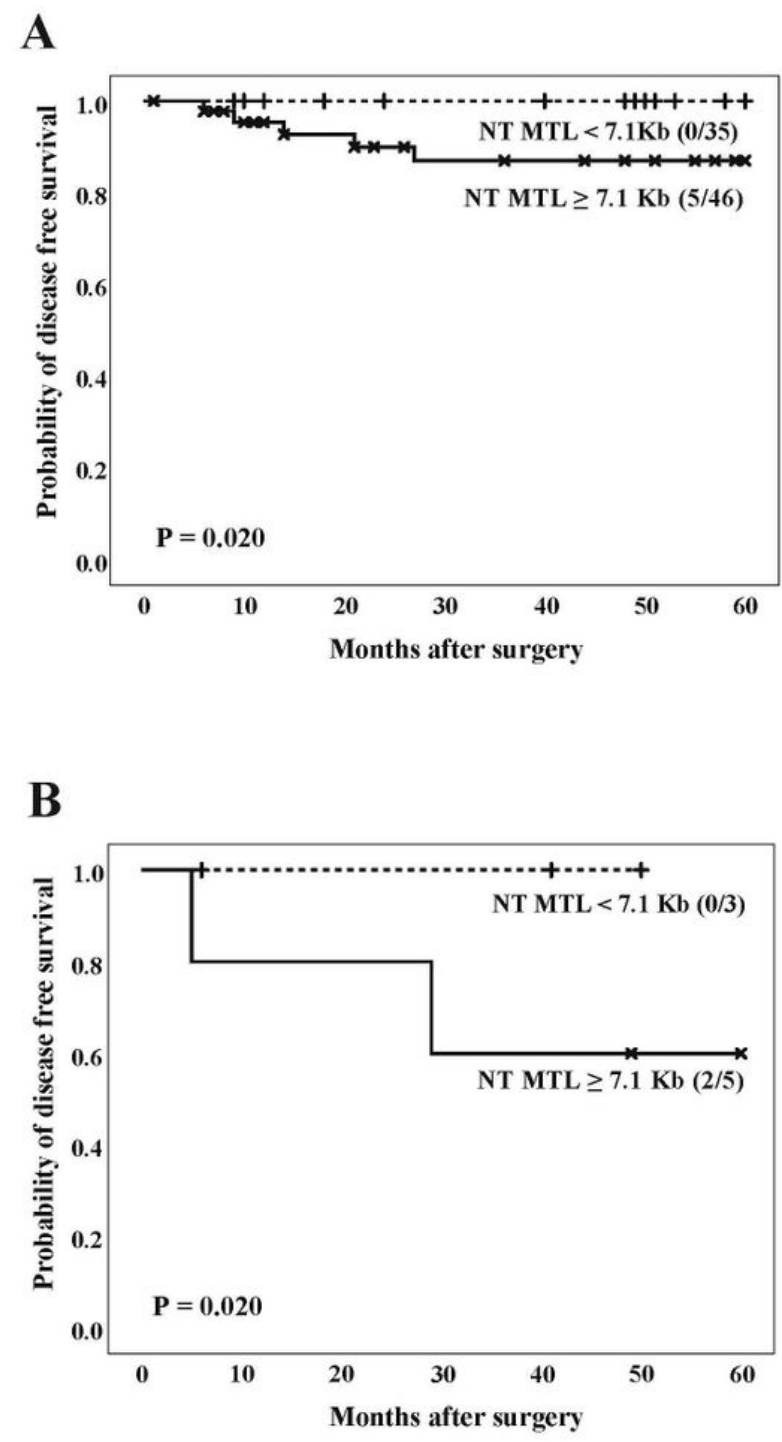

\section{Figure 5}

Kaplan-Meier plots of Disease Free Survival (DFS) considering NT-MLT and BMI of patients. Kaplan-Meier curves in relation to Non-Tumor Mean Telomere Length (NT-MTL) and Body Mass Index (BMI) in Colorectal Cancer population: (A) $\mathrm{BMl}<31.85 \mathrm{~kg} / \mathrm{m} 2$ and (B) BMI $\geq 31.85 \mathrm{~kg} / \mathrm{m} 2$. Numbers in brackets represent cases with tumor recurrence and crosses indicate censored data. 